\title{
CONSIDERAÇÕES ACERCA DO CRITÉRIO DE EQUIPOLÊNCIA DE PENSAMENTOS DE FREGE
}

\author{
Eduardo Antônio Pitt ${ }^{1}$ \\ Universidade Federal do Acre (UFAC) \\ (D) https://orcid.org/0000-0002-0728-3758
}

\begin{abstract}
RESUMO:
Neste artigo faço considerações a respeito da aplicabilidade dos critérios de equipolência de pensamentos de Frege em relação às peculiaridades da linguagem natural e em relação aos casos de identidade de pensamentos compostos. Pretendo apresentar e analisar os critérios de equipolência de pensamentos sugeridos por Frege em duas Cartas a Husserl e em Um breve levantamento de minhas doutrinas lógicas. Meu primeiro objetivo é mostrar que Frege apresenta um critério epistêmico insuficiente e um critério lógico, adequado aos seus objetivos. Em seguida, pretendo testar a aplicabilidade do critério lógico de equipolência perante o embelezamento retórico das linguagens naturais e entre os casos de identidade de pensamentos presentes no artigo Pensamentos Compostos. Dessa forma, meu segundo objetivo é expor qual é a noção de consequência lógica implícita no critério lógico de equipolência. No fim, argumento que a noção de consequência lógica implícita no critério lógico de equipolência não é a noção formal de validade de argumento, mas uma noção intuitiva de consequência lógica.
\end{abstract}

PALAVRAS-CHAVE: Identidade; Pensamentos; Equipolência.

\section{CONSIDERATIONS ABOUT EQUIPOLLENCE CRITERION OF FREGE'S THOUGHT}

\begin{abstract}
:
In this article I do considerations regarding the applicability of equipollence criteria of Frege`s thought in relation to the peculiarities of natural language and in the cases of identity compounds thoughts. I intend to present and analyse the thoughts of equipollence criteria suggested by Frege in two

\footnotetext{
Mestre em Filosofia pela Universidade Federal de Minas Gerais (UFMG), Minas Gerais - Brasil. Professor do Curso de Licenciatura em Filosofia da Universidade Federal do Acre (UFAC), Acre - Brasil. Email: epitt26@yahoo.com.br.
} 
Letters to Husserl and A brief survey of my logical doctrines. My first goal is to show that Frege presented an insufficient epistemic criteria and logical criteria appropriate to their goals. Then, I intend to test the applicability of logical criteria of equipollence before the rhetorical embellishment of natural languages and between the cases of identity thoughts present in article Compounds Thoughts. Thereby, my second goal is to expose what is the notion of consequence implicit logic in logical criteria of equipollence. In the end, I argue that the notion of consequence implicit logic in logical criteria of equipollence is not the formal notion of validity argument, but an intuitive notion of logical consequence.

KEYWORDS: Identity; Thoughts; Equipollence.

\section{Introdução}

O trabalho central de Gottlob Frege (1848 - 1925), conhecido como projeto logicista, resume-se em provar que a aritmética pode ser fundamentada em axiomas lógicos, livres de qualquer intuição. A tese de Frege é que a aritmética possui fundamentos profundamente enraizados nos princípios lógicos, por isso, sustentava que a aritmética possuía o status epistemológico de analítico a priori. Para Frege, as leis fundamentais da lógica, assim como da aritmética, não fazem apelo a fatos particulares porque são leis gerais, daí o seu caráter a priori. O caráter analítico explicase porque essas leis gerais são leis gerais da lógica que são universalmente aplicáveis a toda esfera do conhecimento, isto é, na concepção de Frege, as leis gerais da lógica são aplicáveis irrestritamente a tudo o que é pensável. Dessa forma, a aritmética seria analítica a priori porque seus teoremas seriam deriváveis de definições e leis gerais da lógica.

Para levar a vias de fato o projeto logicista Frege apresenta uma notação conceitual, uma linguagem lógica, no livro Conceitografia (1879), visando demonstrar com rigor e precisão as provas dos teoremas da aritmética. Tal linguagem simbólica atendia às necessidades primordiais para os propósitos de Frege da seguinte maneira: o método de condução de provas era axiomático e o uso de axiomas lógicos garantia a exclusão de qualquer apelo à intuição, uma vez que, a justificação verdadeira dos teoremas da aritmética dependia exclusivamente da verdade dos axiomas, das definições e das regras de inferência contidas no sistema.

Apesar de Frege optar por uma lógica extensional, implicitamente no artigo Função e Conceito (1891) e em Crítica a Husserl: Filosofia da Aritmética I (1894) e explicitamente em Comentários sobre o Sentido e a Referência (1892/1895), encontra-se em algumas obras, deste autor, formulações para um tal critério de equipolência de pensamentos. Em decorrência dos problemas provenientes da formulação destes critérios é que, neste artigo, apresento e analiso os critérios de equipolência de 
pensamentos de Frege.

Para uma melhor discussão a respeito do tema irei dividir o artigo em duas partes. Começo analisando os critérios de equipolência de pensamentos apresentados em Um breve levantamento de minhas doutrinas lógicas e em Carta a Husserl, ambos de 1906. No decorrer da análise irei argumentar que Frege apresenta dois critérios, um de caráter epistêmico que julgamos insuficiente e outro de caráter lógico.

Em seguida, levando em consideração o critério lógico de equipolência de pensamentos irei analisar a aplicabilidade deste em relação a alguns casos de identidade de pensamentos apresentados por Frege em seus textos. Irei analisar casos de equipolência de pensamentos expressos por sentenças assertivas simples e sentenças assertivas compostas.

Com este expediente, meu objetivo é expor qual a noção de consequência lógica está implícita no critério lógico de equipolência de pensamentos. Ou seja, pretendo mostrar se é a noção do critério formal de consequência lógica (um argumento é válido quando sua forma é válida) ou se é a noção intuitiva de consequência lógica, onde a validade de um argumento é estabelecida pelo critério de necessidade da preservação da verdade definido em termos modais (um argumento é válido quando em todos os mundos possíveis ${ }^{2}$ é impossível premissas verdadeiras e conclusão falsa) e, neste caso, a preocupação com a forma do argumento e a distinção entre símbolos lógicos e não lógicos deixa de ser essencial.

\section{Os critérios de equipolência de pensamentos de Frege}

Frege apresenta sua primeira versão para um critério de equipolência de pensamentos em Um breve levantamento de minhas doutrinas lógicas, vejamos:

Agora duas sentenças $A$ e $B$ podem estar em uma relação que qualquer um que reconhece o conteúdo de $A$ como verdadeiro precisa imediatamente reconhecer o de $B$ como verdadeiro, e vice-versa, que qualquer um que aceita o conteúdo de $B$ deve imediatamente aceitar o de $A$ (equipolência). Aqui está sendo assumido que não existe dificuldade em entender o conteúdo de $A$ e de $B$. (...). Eu assumo que nada existe no conteúdo de qualquer uma das duas sentenças equipolentes $A$ e $B$ que seria imediatamente aceito como verdadeiro por qualquer um que a tinha compreendido corretamente. (...). Assim, temos que separar do conteúdo de uma sentença somente a parte que pode ser aceita como verdadeira ou rejeitada como falsa. Eu chamo esta parte o pensamento expressado pela sentença. Ele é o mesmo em sentenças equipolentes do tipo dado acima. (Frege, 1906, pp. 299-300).

2 A noção de "mundos possíveis" é aqui usada no sentido de uma condição hipotética que nos permite pensar o universo diferente do que é. 
Pela forma que Frege apresenta o critério de equipolência acima, podemos considerá-lo um critério de caráter epistêmico, pois tal critério leva em consideração a capacidade cognitiva de um falante racional e competente de reconhecer o mesmo pensamento sendo expresso por duas sentenças diferentes $A$ e $B$. A nossa opinião é que essa versão do critério de equipolência é insuficiente porque da maneira que foi formulada por Frege, tal critério pode criar tensões com os próprios escritos de Frege.

Considere, por exemplo, as sentenças: $4^{2}=4^{2}$ e $4.4=4^{2}$. Conforme a citação acima, qualquer falante competente, racional e conhecedor de pequenas operações aritméticas, irá reconhecer as duas sentenças como verdadeiras e irá aceitar o conteúdo de ambas as sentenças imediatamente. Sendo que, são essas as condições exigidas pelo critério epistêmico de equipolência, teríamos então que considerar $4^{2}=4^{2}$ e $4.4=4^{2}$ expressando um único pensamento. Na linguagem natural também ocorre o mesmo. Se eu sei que a estrela da tarde = a estrela da manhã, então eu aceitaria e reconheceria de imediato a verdade das duas sentenças: A estrela da tarde é Vênus e A estrela da manhã é Vênus. Logo, pelo critério epistêmico de equipolência, as duas sentenças são equipolentes. Certamente essas equipolências vão contra os escritos de Frege. Em suma, na concepção de Frege, estas sentenças possuem identidade de referência, mas certamente expressam sentidos diferentes.

Com isso, concluímos que um critério epistêmico de equipolência formulado da maneira do acima, isto é, baseado apenas no reconhecimento da verdade ou falsidade do conteúdo que é expresso nos pensamentos, não consegue determinar objetivamente quando duas sentenças diferentes expressam o mesmo pensamento. Entendemos que tal falta seria suprimida por um critério de equipolência de caráter lógico que assegure a objetividade e a validade da análise a respeito da identidade de pensamentos.

Parece que Frege pensava assim, uma vez que, em Carta a Husserl apresenta um critério de equipolência de caráter lógico que possibilita a análise necessária para o reconhecimento de equipolência entre sentenças diferentes. Vejamos:

Agora, me parece que o único meio possível de decidir se a proposição $A$ expressa o mesmo pensamento que a proposição $B$ é o seguinte, e aqui eu assumo que nenhuma das duas proposições contém um componente de sentido logicamente evidente. Se ambas as pressuposições que o conteúdo de $A$ é falso e o de $B$ verdadeiro e a pressuposição que o conteúdo de $A$ é verdadeiro e o de $B$ falso conduzem a uma contradição lógica, e se isto pode ser estabelecido sem sabermos se o conteúdo de $A$ ou $B$ é verdadeiro ou falso e sem exigir nada mais do que leis puramente lógicas para este propósito, então nada pode pertencer ao conteúdo de $A$ enquanto é suscetível de 
ser julgado verdadeiro ou falso, que não pertença também ao conteúdo de $B$; pois não haveria base em geral no conteúdo de $B$ para qualquer tal excesso, e de acordo com a pressuposição acima, tal excesso não seria logicamente evidente. No mesmo modo, dada nossa pressuposição, nada pode pertencer ao conteúdo de $B$, enquanto suscetível de ser julgado verdadeiro ou falso, exceto que também pertença ao conteúdo de $A$. Assim, o que é capaz de ser julgado verdadeiro ou falso nos conteúdos de $A$ e $B$ são idênticos e somente isto é de comprometimento da lógica e é o que eu chamo o pensamento expressado por ambos $A$ e $B$. (Frege, 1906, pp. 305-306).

Dado o critério lógico de equipolência, entendemos que fica notório quando Frege exige somente o uso de leis lógicas para se chegar à contradição, que os pensamentos sejam analisados em uma linguagem formalizada. Dessa forma, sendo que expressamos pensamentos por meio de sentenças assertivas, devemos para a correta aplicação do critério lógico de equipolência, analisar os pensamentos por meio das sentenças assertivas que os expressam. Por isso, as sentenças sob análise devem ser traduzidas para uma linguagem formalizada para que sejam respeitadas as condições lógicas e, se for o caso, derivar logicamente a contradição.

Sabemos que Frege considerava a linguagem natural um instrumento imperfeito para a expressão de pensamentos por causa das diversas peculiaridades que esta possui. É nesse sentido que uma linguagem logicamente perfeita atua como um microscópio apurando a linguagem natural. O próprio Frege explicita esta preocupação com as linguagens naturais, quando em Carta a Husserl diz "não pode ser tarefa da lógica investigar a linguagem e determinar o que está contido em uma expressão linguística. (...). A principal tarefa da lógica é libertar-se da linguagem e simplificá-la" (Frege, 1997, p. 303).

Pode-se conjecturar que Frege parecia estar disposto a considerar as peculiaridades da linguagem natural e que o seu critério lógico de equipolência deveria ter meios de separar o pensamento das roupagens da linguagem natural. Porém, de acordo com as condições expostas no critério lógico de equipolência, estamos em condições de afirmar que pelo posicionamento antipsicologista de Frege, este não tinha a mínima preocupação em dar conta das peculiaridades da linguagem natural. No artigo O Pensamento (1918) Frege é muito claro ao dizer que "uma sentença assertiva encerra frequentemente, além do pensamento e da asserção, um terceiro componente ao qual não se aplica a asserção" (Frege, 2002, p. 18) e esse terceiro elemento não pertence à exposição científica devendo ser desconsiderado.

Por isso, no critério lógico de equipolência não encontramos nenhuma consideração a favor das peculiaridades da linguagem natural, somente a recomendação de Frege que devemos unicamente considerar o pensamento e desconsiderar aquilo que ele chama de o colorido da 
linguagem. Em Carta a Husserl, Frege diz que a vantagem em agir dessa forma é que "uma vez decidido tomar este passo, abolimos de uma vez só com uma massa confusa de distinções inúteis e com a ocasião para inúmeras disputas que não podem ser decididas na maior parte objetivamente" (Frege, 1997, p. 302).

Sendo assim, Frege quis se libertar das distinções irrelevantes que fazem parte somente da linguagem natural e que não são relevantes para a lógica. No artigo $O$ Pensamento (Frege, 1918, pp. 15-22) encontramos uma lista dessas distinções irrelevantes:

* O uso de é verdade nas sentenças nada acrescenta ao pensamento.

* Não pertence ao pensamento aquilo que diz respeito à entonação ou a escolha psicológica das expressões, por isso, não faz diferença usarmos as palavras cavalo, corcel, ginete ou rocim.

* Não pertence ao pensamento insinuações do discurso que ocorrem com as palavras ainda ou já em sentenças do tipo: Alfredo ainda não chegou, pois queremos mesmo é dizer que Alfredo não chegou.

* Não faz diferença ao pensamento se transformamos uma sentença da voz ativa para passiva e vice-versa.

* Expressões com indexicais do tipo eu, você, aqui, ali, lá, agora, isto, aquilo, hoje, ontem e similares, devem expressar rigorosamente o contexto de declaração para que seja mantida a expressão do pensamento.

Porém, esse libertar-se da linguagem não pode ser levado ao pé da letra porque Frege havia dito em Sobre o Sentido e a Referência (1892) "dificilmente se poderá negar que a humanidade possui um estoque comum de pensamentos que é transmitido de uma geração para outra" (Frege, 1997, p. 154). Isso quer dizer, como diz Weiner, "que este estoque comum de pensamentos têm sido transmitidos através da linguagem natural" (Weiner, 2008 , p. 266) o que, em nossa opinião, significa que Frege não descarta a possibilidade de aplicar o seu critério lógico de equipolência em sentenças da linguagem natural, se estas forem traduzidas para uma linguagem formalizada, que é o instrumento mais correto para se analisar a expressão de pensamentos.

Um exemplo disso encontra-se em A Generalidade Lógica (1923), pois Frege aponta um caso onde ocorrem diferenças na linguagem natural para expressar a generalidade e defende que as diferenças irrelevantes devem ser deixadas de lado no momento da tradução dessas sentenças em uma linguagem formalizada. Frege apresenta as sentenças "Todos os homens são mortais', 'Cada homem é mortal' e 'Se algo é um homem, ele é mortal'” (Frege, 2002, p. 95) que expressam o mesmo pensamento e que devem ser formalizadas na forma única da sentença hipotética $\forall \mathrm{x}(\mathrm{Hx} \rightarrow$ $\mathrm{Mx}$ ). Com tal formalização, aplicando o critério lógico de equipolência em duas dessas três sentenças, a suposição que uma é verdadeira e a outra falsa conduzirá à contradição lógica, caracterizando a equipolência entre essas sentenças da linguagem natural. 
A seguir, aplico o critério lógico de equipolência nos exemplos, que o próprio Frege cita em seus textos, para conhecermos a aplicabilidade deste critério. Levo em consideração os exemplos da linguagem natural. Assim, conheceremos o funcionamento do critério lógico de equipolência diante das inúmeras peculiaridades da linguagem natural. Começo analisando a aplicabilidade do critério lógico de equipolência entre sentenças equipolentes simples e, após, passo a análise para os casos entre sentenças equipolentes compostas.

\section{Os casos de equipolência entre pensamentos simples}

Irei aplicar o critério lógico de equipolência de Frege nos exemplos com a linguagem natural e saberemos como este critério se comporta diante às peculiaridades que ocorrem em linguagens que não têm o mesmo rigor semântico que as linguagens formais. Em se tratando destes exemplos relativos à linguagem natural, analiso os exemplos citados por Frege em Lógica (Frege, 1879-1891, pp. 140-141), que seguem abaixo:

1. M deu o documento A para $\mathrm{N}$.

$\mathrm{O}$ documento A foi dado a $\mathrm{N}$ por $\mathrm{M}$.

$\mathrm{N}$ recebeu o documento A de $\mathrm{M}$.

2. Frederico o Grande venceu a batalha de Rossbach.

É verdade que Frederico o Grande venceu a batalha de Rossbach.

3. Este cachorro uivou a noite inteira.

Este vira-lata uivou a noite inteira.

Esses três exemplos são análogos a outros casos apresentados por Frege em outros textos. O exemplo da Conceitografia, "Os Gregos venceram os Persas em Platea e Os Persas foram vencidos pelos Gregos em Platea" (Frege, 1967, p. 12) é representado aqui por (1). No artigo, $O$ Pensamento, Frege apresenta um caso representado aqui por (2) que é "Sinto um perfume de violetas e É verdade que sinto um perfume de violetas" (Frege, 2002, p. 15) e, no mesmo artigo, temos um caso representado aqui por (3) que é "não faz nenhuma diferença para o pensamento se uso a palavra cavalo, corcel, ginete ou rocim" (Frege, 2002, p. 19). Porém, temos ainda que acrescentar a nossa lista acima mais dois casos apresentados no artigo $O$ Pensamento (Frege, 2002, pp. 19-20), são estes:

4. Alfredo ainda não chegou.

Alfredo não chegou.

5. Expressões com indexicais. Exemplo:

Hoje choveu no centro de Rio Branco (pronunciado dia 25/06/2012).

Ontem choveu no centro de Rio Branco (pronunciado dia 26/06/2012).

Sendo assim, tenho que primeiro traduzir as sentenças dos cinco casos da lista acima para uma linguagem logicamente perfeita para depois aplicar o critério lógico de equipolência para sabermos se chegamos a 
alguma contradição lógica.

Agora, antes de aplicar o critério lógico de equipolência nestas sentenças da linguagem natural quero dizer que a recomendação de Frege é que devemos desconsiderar tais diferenças porque elas não afetam o pensamento expressado. Isto nos leva a crer que a preocupação de Frege com identidade de pensamentos não diz respeito às linguagens naturais. Contudo, queremos saber como o critério lógico de equipolência atua sobre a linguagem natural se esta for formalizada em uma linguagem lógica.

Assim, para não perdermos tempo com diferenças insignificantes, deixo de lado aqueles casos onde as duas sentenças podem ser traduzidas com uma única forma lógica. Nesse sentido, entendo que no caso (2) a ocorrência das palavras é verdade e no caso (4) a ocorrência da palavra ainda não são suficientes para impedir que as respectivas sentenças recebam a mesma formalização lógica. Com isso, irei aplicar o critério lógico de equipolência somente nos casos (1), (3) e (5), pois nesses casos, os respectivos pares de sentenças serão formalizados de formas diferentes, o que torna a aplicação e a análise do critério lógico de equipolência mais interessante. Isto é, depois de traduzir as respectivas sentenças para uma linguagem logicamente perfeita e tendo aplicado o critério lógico de equipolência nelas, basta verificar se os respectivos argumentos são válidos classicamente ou teremos que assumir o critério de necessidade de preservação da verdade.

No caso (1) ocorre três sentenças variando entre as formas ativa e passiva. Não há necessidade de aplicar o critério lógico de equipolência nas três sentenças, uma vez que, elas são equipolentes e o resultado será o mesmo caso a análise seja feita com apenas duas, por exemplo, $M$ deu o documento A para $N$ e $N$ recebeu o documento $A$ de $M$. Nestas sentenças ocorre duas expressões relacionais diferentes e pelo recurso das relações inversas pode-se formalizar as sentenças da seguinte maneira:

$\mathrm{M}$ deu o documento A para $\mathrm{N}=\mathrm{Bman}$.

$\mathrm{N}$ recebeu o documento A de $\mathrm{M}=\mathrm{B}^{-1}$ nam.

Agora, aplicando o critério lógico de equipolência tem-se os seguintes argumentos:

* ( $\neg$ Bman $\Lambda \mathrm{B}^{-1}$ nam $)-\perp$

* (Bman $\Lambda \neg \mathrm{B}^{-1}$ nam $)-\perp$

Como estou analisando a identidade de pensamentos dentro de uma linguagem formalizada, que pode ser a notação conceitual de Frege, então espera-se que a noção de consequência lógica implícita nos dois argumentos acima seja a do critério formal. Com isso, para ver se os dois argumentos acima são válidos leva-se em conta a forma lógica dos argumentos. O que significa dizer que se os dois argumentos acima são válidos classicamente, então independentemente do domínio do discurso e da interpretação que damos aos símbolos não lógicos nunca teremos premissas verdadeiras e conclusão falsa o que, neste caso, quer dizer que nunca teremos premissas 
verdadeiras, pois a conclusão já é o falso, sendo uma contradição lógica.

Acontece que para os dois argumentos acima serem válidos, com o critério formal de consequência lógica, deve-se adicionar uma premissa adicional para assegurar que a contradição seja derivada em qualquer interpretação possível. Esta premissa adicional seria do tipo: $\forall \mathrm{x} \forall \mathrm{y}(\mathrm{Rxy} \leftrightarrow$ $\mathrm{R}^{-1} \mathrm{yx}$ ). Porém, ao adicionar a premissa na derivação da contradição, estou violando as exigências de Frege na formulação do critério lógico de equipolência, pois, a contradição não foi derivada somente com o uso de leis puramente lógicas, mas somente em virtude da premissa adicional. Dessa forma, fica injustificável considerar que a noção de consequência lógica implícita no critério lógico de equipolência seja a do critério formal.

Contudo, precisa haver algum critério que faça com que os dois argumentos sejam válidos. Entendo que, como a análise é sobre um critério intensional, a preocupação com a forma do argumento e a distinção entre símbolos lógicos e não lógicos deixa de ser essencial porque a contradição lógica deve ocorrer não exclusivamente no nível da forma lógica do argumento, mas principalmente em função dos significados de seus termos. Logo, parece plausível aceitar que a noção de consequência lógica implícita no critério lógico de equipolência é baseada no critério de necessidade da preservação da verdade definido em termos modais, isto é, implícita na noção intuitiva de consequência lógica.

Neste sentido, o critério de necessidade torna válido os dois argumentos analisados, uma vez que, em qualquer mundo possível onde afirma-se um pensamento e nega-se o outro na premissa é impossível termos premissas verdadeiras e a conclusão falsa. Pelo menos no significado dos termos é impossível a premissa ser verdadeira, pois ela é contraditória.

No caso (3) ocorre duas sentenças com a mesma expressão funcional e podemos formalizá-la utilizando a mesma constante de predicado $(F)$ para as duas sentenças. $\mathrm{O}$ mesmo não acontece com as expressões de argumento que são diferentes e devem ser formalizadas com constantes individuais diferentes. Pela presença do termo indicativo este na expressão do argumento, quero deixar claro que estou usando o recurso da nomeação por ostensão e, dessa forma, estou definindo por ostensão o significado dos nomes $a$ e $b$. Por conta desse expediente, $a$ e $b$ se tornam designadores rígidos e a igualdade $a=b$ é válida em todos os mundos possíveis. Então usarei para Este cachorro $=a$ e para Este vira-lat $a=b$ e assim, as sentenças serão formalizadas da seguinte maneira:

Este cachorro uivou a noite inteira $=\mathrm{Fa}$.

Este vira-lata uivou a noite inteira $=\mathrm{Fb}$.

E aplicando o critério lógico de equipolência tem-se os seguintes argumentos:

$*(\neg \mathrm{Fa} \Lambda \mathrm{Fb})-\perp$

* $(\mathrm{Fa} \Lambda \neg \mathrm{Fb})-\perp$

No caso (5) também ocorre duas sentenças com a mesma expressão 
funcional o que permite uma única constante de predicado $(G)$ para as duas sentenças. A diferença entre elas ocorre no indexical que está no lugar do argumento marcando o dia do proferimento do pensamento e, por isso, utilizarei constantes individuais diferentes. As sentenças serão formalizadas assim:

Hoje choveu no centro de Rio Branco (pronunciado em 25/06) = Ga.

Ontem choveu no centro de Rio Branco (pronunciado em 26/06) $=\mathrm{Gb}$.

E aplicando o critério lógico de equipolência tem-se os seguintes argumentos:

$*(\neg \mathrm{Ga} \Lambda \mathrm{Gb}) \vdash \perp$

$*(\mathrm{Ga} \Lambda \neg \mathrm{Gb})-\perp$

Agora, na análise dos casos (3) e (5), usarei o método de contra exemplo semântico e pretendo mostrar que tais argumentos não são válidos classicamente porque é fácil encontrar uma circunstância em que temos premissas verdadeiras e conclusão falsa.

Como os argumentos (3) e (5) são análogos quanto à estrutura simbólica apresento apenas um contra exemplo semântico para refutá-los. Considere o primeiro argumento do caso (3), $(\neg \mathrm{Fa} \Lambda \mathrm{Fb}) \vdash \perp$. Quando $F=x$ é filósofo, $a=$ Pelé e $b=$ Platão sendo os conjuntores verdadeiros temos premissa verdadeira e a conclusão falsa.

Com isso, deve-se assumir também nos exemplos com a linguagem natural o critério de necessidade de preservação da verdade. Somente assim o critério lógico de equipolência fará surgir no nível dos significados dos termos a contradição lógica. Assim, segundo os respectivos pares de sentenças dos exemplos de Frege, casos (1), (3) e (5), e segundo o critério de necessidade definido em termos modais, é impossível premissa verdadeira e conclusão falsa, pois, é impossível premissas verdadeiras.

Sendo assim, concluo esta parte do artigo afirmando que segundo os exemplos de Frege de equipolência com a linguagem natural, a aplicabilidade do critério lógico de equipolência só entra em acordo com suas afirmações se consideramos o critério de necessidade de preservação da verdade como a noção de consequência lógica implícita no critério lógico de equipolência. Em se tratando de um critério de identidade intensional isto é compreensível, uma vez que, nesse caso, a forma lógica do argumento não deve ser essencial para a validade do mesmo, pois a análise deve se debruçar sobre os significados dos termos em consideração.

Frege em nenhum texto autoriza ou desautoriza esta conclusão. $\mathrm{O}$ fato de Frege ser um lógico clássico e assumir uma noção de consequência lógica que não seja a clássica em seu critério de equipolência lógico é, sem dúvida, um resultado estranho, mas que é inevitável para um critério de identidade intensional. Sob outro ponto de vista, manter Frege fiel às noções clássicas da lógica implica concluir que Frege não tinha um critério lógico de equipolência bem formulado. Por enquanto não irei assumir nenhuma das duas opções porque irei prosseguir a análise do critério lógico de 
equipolência em outros casos de identidade de pensamentos e veremos no final o que podemos concluir.

\section{Os casos de equipolência de pensamentos compostos}

Irei apresentar e analisar os casos de equipolência que Frege apresenta no artigo Pensamentos Compostos (1923). Tais casos são de natureza totalmente diferente dos que até agora analisei porque nestes casos a equipolência não ocorre entre dois pensamentos simples, mas entre dois pensamentos compostos.

Em suma, um pensamento composto é um "caso particular de composição de pensamentos, isto é, a situação em que dois pensamentos se combinam por meio de um conectivo lógico insaturado de modo que o sentido do todo seja um único pensamento" (Frege, 2002, p. 68). Dessa forma, se $A$ e $B$ expressam cada um diferentes pensamentos e os colocamos em conjunção, temos um pensamento composto da forma (A $\Lambda \mathrm{B})$.

A presença do conectivo na composição do pensamento composto é fundamental porque ele representa a parte insaturada que necessita de complementação. Segundo Weiner, "a principal diferença é a caracterização de Frege desses conectivos vero funcionais como expressando funções que tomam pensamentos como argumentos e retornam pensamentos compostos como valores" (Weiner, 2005, p. 156). Os outros componentes nessa composição são os próprios pensamentos simples que, por sua vez, já são por si só completos e saturados.

A análise que Frege faz em Pensamentos Compostos parte de seis espécies de pensamentos compostos que podem ser considerados como casos base de pensamentos compostos. Frege faz uso de três conjuntos de conectivos para expressá-los e a interpretação dos conectivos é vero funcional, os conjuntos são $(\neg, \Lambda),(\neg, \rightarrow),(\neg, \mathrm{V})$.

À primeira vista, parece que Frege abandona o par de conectivos $(\neg$, $\rightarrow$ ) que o acompanhava desde a Conceitografia porque as seis espécies de pensamentos compostos são primeiramente apresentadas pelo par de conectivos primitivos $(\neg, \Lambda)$. Contudo, esta seria uma conclusão precipitada, pois Frege estabelece a interdefinibilidade dos conectivos lógicos e isto possibilita, a partir de qualquer um dos três pares de conectivos, expressar todos os outros. Frege chega mesmo a assumir que "nenhuma dessas espécies pode ter precedência sobre as demais. Cada uma delas pode servir de base para a derivação das outras" (Frege, 2002, pp. 86-87).

Aqui não faço uma exposição individual e pormenorizada de todas as seis espécies de pensamentos compostos. Dado as informações acima, apresento duas listas abaixo: a primeira, contendo as seis espécies de pensamentos compostos (casos base) e pela interdefinibilidade as equipolências e, a segunda, contendo equipolências entre pensamentos compostos formados por um único pensamento. Note que, na segunda lista 
há casos também de equipolência ocorrendo entre um pensamento simples e um pensamento composto.

Chamo atenção também para o fato de usar nestas listas o sinal $(=$ eq. $)$ para simbolizar a relação de equipolência entre os pensamentos compostos. Isto facilita a exposição, mas é preciso ficar entendido que Frege em seus textos publicados nunca apresentou um sinal para expressar a relação de equipolência. Vejamos os casos:

Casos base (primeira coluna) e por interdefinibilidade temos as equipolências:

1: $(\mathrm{A} \Lambda \mathrm{B})=_{\text {eq. }}(\mathrm{B} \Lambda \mathrm{A})=_{\text {eq. }} \neg(\neg \mathrm{A} \vee \neg \mathrm{B})==_{\text {eq. }} \neg(\mathrm{A} \rightarrow \neg \mathrm{B})$

2: $\neg(\mathrm{A} \Lambda \mathrm{B})==_{\text {eq. }} \neg(\mathrm{B} \Lambda \mathrm{A})==_{\text {eq. }}(\neg \mathrm{A} \vee \neg \mathrm{B})=$ eq. $(\mathrm{A} \rightarrow \neg \mathrm{B})$

3: $(\neg \mathrm{A} \Lambda \neg \mathrm{B})==_{\text {eq. }}(\neg \mathrm{B} \Lambda \neg \mathrm{A})=$ eq. $\neg(\mathrm{A} \vee \mathrm{B})==_{\text {eq. }} \neg(\neg \mathrm{A} \rightarrow \mathrm{B})$

4: $\neg(\neg \mathrm{A} \Lambda \neg \mathrm{B})==_{\text {eq. }} \neg(\neg \mathrm{B} \Lambda \neg \mathrm{A})=$ eq. $(\mathrm{A} \vee \mathrm{B})==_{\text {eq. }}(\neg \mathrm{A} \rightarrow \mathrm{B})$

5: $(\mathrm{A} \Lambda \neg \mathrm{B})==_{\text {eq. }}(\neg \mathrm{B} \Lambda \mathrm{A})=$ eq. $\neg(\neg \mathrm{A} \vee \mathrm{B})==_{\text {eq. }} \neg(\mathrm{A} \rightarrow \mathrm{B})$

6: $\neg(\mathrm{A} \Lambda \neg \mathrm{B})==_{\text {eq. }} \neg(\neg \mathrm{B} \Lambda \mathrm{A})=$ eq. $_{\text {e }}(\neg \mathrm{A} \vee \mathrm{B})==_{\text {eq. }}(\mathrm{A} \rightarrow \mathrm{B})$

Casos de pensamentos compostos formados por um único pensamento:

7: $\mathrm{A}={ }_{\text {eq. }}(\mathrm{A} \Lambda \mathrm{A})=_{\text {eq. }}(\mathrm{A} \vee \mathrm{A})==_{\text {eq. }} \neg(\neg \mathrm{A} \Lambda \neg \mathrm{A})={ }_{\text {eq. }} \neg \neg \mathrm{A}$

8: $\neg \mathrm{A}==_{\text {eq. }} \neg(\mathrm{A} \Lambda \mathrm{A})==_{\text {eq. }}(\neg \mathrm{A} \Lambda \neg \mathrm{A})$

9: $\neg(\mathrm{A} \Lambda \neg \mathrm{A})==_{\text {eq. }} \neg(\neg \mathrm{A} \Lambda \mathrm{A})==_{\text {eq. }}(\mathrm{A} \rightarrow \mathrm{A})$

Levando-se em conta cada um dos nove casos de equipolência entre pensamentos compostos é fácil notar que no artigo Pensamentos Compostos Frege somente apresenta casos de equipolência entre esquemas de fórmulas tautologicamente equivalentes. Isto levanta a dúvida, como bem aponta Thiel, "em virtude desses exemplos estamos inclinados a considerar a equivalência lógica de duas proposições como critério de sua igualdade de sentido, pelo menos no caso de enunciados desse tipo" (Thiel, 1972, p. 147). Ou seja, seria legítimo considerar a noção de equivalência tautológica condição suficiente e necessária para equipolência de pensamentos compostos?

Ora, entendo que considerar a noção de equivalência tautológica uma condição suficiente para duas expressões serem equipolentes é uma interpretação errada porque Frege não concordaria que todas as equivalências tautológicas são equipolentes. Por exemplo, não há motivo para Frege discordar que a lei do terceiro excluído $(\alpha \mathrm{v} \neg \alpha)$ não expressa o mesmo pensamento que a lei de Peirce $(((\alpha \rightarrow \beta) \rightarrow \alpha) \rightarrow \alpha)$, assim como nenhuma das duas expressam o mesmo pensamento que o princípio da identidade $(\alpha \rightarrow \alpha)$.

No caso de equivalência tautológica ser condição necessária para equipolência parece que a resposta também é negativa dado os exemplos de Frege com pensamentos simples. Mostrei acima exemplos de sentenças da linguagem natural que classicamente não são tautologicamente equivalentes, mas que são equipolentes para Frege. Agora, considerando somente os nove casos de pensamentos compostos, deve-se concluir que equivalência tautológica é condição necessária para equipolência porque se duas 
proposições não são tautologicamente equivalentes, então elas não são equipolentes.

De qualquer forma, o importante é eliminar a dúvida apontada por Thiel acima e deixar claro que o critério de equipolência lógico é mais refinado que a noção de equivalência tautológica. Isto está claro, na medida em que, não basta ser uma equivalência tautológica para expressar o mesmo pensamento para Frege, ou seja, a discussão a respeito da equipolência de pensamentos vai além da relação entre proposições tautologicamente equivalentes.

Bermúdez é outro autor que apresenta uma posição que merece ser discutida. Segundo Bermúdez, os casos apresentados por Frege em Pensamentos Compostos não asseguram que há ocorrência de equipolência entre eles porque "está claro que ele (Frege) não precisa afirmar que $B$ e sua dupla negação são sinônimas. A inferência funciona perfeitamente bem sobre a equivalência lógica de $B$ para $\neg \neg B$ " (Bermúdez, 2003, p. 16). Concedo em parte à opinião de Bermúdez, pois este tem razão em dizer que a inferência de $B$ para $\neg \neg B$ e vice-versa é válida pela relação de equivalência lógica. Porém, discordo quando Bermúdez diz que Frege não estava afirmando em Pensamentos Compostos que $B$ e $\neg \neg B$ expressam o mesmo pensamento.

Entendo que Bermúdez teria completa razão se no artigo Pensamentos Compostos Frege dá maior ênfase ao plano lógico do que ao plano dos sentidos das expressões. Mas não é isso o que acontece, por exemplo, Frege afirma que podemos entender a permutabilidade das expressões nas equipolências ( $\mathrm{A} \Lambda \mathrm{B})$ e $(\mathrm{B} \Lambda \mathrm{A})$ sem qualquer tipo de demonstração lógica bastando apenas que nós tomemos consciência do seu sentido. Depois, o próprio Frege diz que "não se deve aqui (...) entender essa permutabilidade como um teorema, pois não há, no domínio do sentido nenhuma diversidade entre essas expressões" (Frege, 2002, p. 73).

Assim, parece que Bermúdez interpreta os casos de equipolência como casos que podem ser reduzidos à relação de equivalência lógica. Que os casos de equipolência apresentados em Pensamentos Compostos são todos tautologicamente equivalentes é um fato inquestionável, mas daí reduzir a relação de equipolência à relação de equivalência tautológica entendo ser um erro como argumentei acima.

Volto agora à análise dos casos de equipolência entre pensamentos compostos. Irei aplicá-los no critério lógico de equipolência como estamos fazendo com todos os exemplos de Frege sobre equipolência.

Uma vez que, todos os nove casos de equipolência entre pensamentos compostos ocorrem somente entre esquemas de fórmulas que são tautologicamente equivalentes, não aplicarei o critério lógico de equipolência em todos os casos, pois a conclusão que vale para um caso valerá para todos os outros. Assim, concentrarei minha análise na primeira espécie de equipolência entre pensamentos compostos: 
* $(\mathrm{A} \Lambda \mathrm{B})=$ eq. $_{\text {e }}(\mathrm{B} \Lambda \mathrm{A})=_{\text {eq. }} \neg(\neg \mathrm{A} \vee \neg \mathrm{B})==_{\text {eq. }} \neg(\mathrm{A} \rightarrow \neg \mathrm{B})$

Aqui ocorre quatro pensamentos compostos expressando um único pensamento e como estes esquemas de fórmulas são tautologicamente equivalentes não é difícil prever que quando aplicarmos o critério lógico de equipolência, em qualquer dupla de fórmulas acima, tem-se sempre como premissa uma conjunção falsa. Veja duas combinações possíveis:

* $\{(\mathrm{A} \Lambda \mathrm{B}) \Lambda \neg(\mathrm{B} \Lambda \mathrm{A})\} \vdash \perp$

* $\{\neg(\neg \mathrm{A} V \neg \mathrm{B}) \Lambda \neg \neg(\mathrm{A} \rightarrow \neg \mathrm{B})\} \vdash \perp$

$\mathrm{O}$ resultado não poderia ser outro, pois estou a mando do critério lógico de equipolência afirmando e negando ao mesmo tempo duas fórmulas tautologicamente equivalentes e aqui, como em todos os outros casos de pensamentos compostos, uma das duas será verdadeira e a outra falsa, fazendo com que a premissa seja falsa. Dizendo classicamente, pela forma dos dois argumentos acima não há circunstância possível que faça a premissa (a conjunção) ser verdadeira e a conclusão (a contradição lógica) falsa porque, nesses exemplos, com fórmulas tautologicamente equivalentes é impossível ter premissas verdadeiras.

Assim, nestes exemplos de pensamentos compostos de Frege, sempre ocorre premissas falsas conforme o critério lógico de equipolência. Desta forma, concluímos que todos os respectivos argumentos são válidos classicamente. Este resultado representa uma controvérsia porque nos casos de pensamentos simples o critério lógico de equipolência só é aplicável com o critério de necessidade da preservação da verdade, mas, nos casos de pensamentos compostos o critério lógico de equipolência já é aplicável com o critério formal de preservação da verdade. Como equalizar esses resultados se os dois critérios são diferentes? O que concluir a respeito da aplicabilidade do critério lógico de equipolência de Frege?

\section{Conclusões}

Uma forma de encontrar uma resposta para as perguntas é primeiro definir o quanto deve-se dar importância ao resultado alcançado ao aplicar o critério lógico de equipolência nos casos de pensamentos compostos. Digo, pode-se amenizar a controvérsia encontrada entendendo que o critério formal de consequência lógica só entrou em vigor nestes casos devido à característica especial destes exemplos serem entre pensamentos compostos tautologicamente equivalentes. Isso fez com que inevitavelmente sempre que aplicamos o critério lógico de equipolência nesses casos a premissa do argumento seja sempre falsa e isto torna classicamente válido os respectivos argumentos. finais:

Esta informação é importante e a partir dela faço três considerações

(i) por serem pensamentos compostos tautologicamente equivalentes parece que a equipolência firmada entre eles é trivial sendo válida pelo 
critério formal e pelo critério de necessidade de consequência lógica.

(ii) argumentei que a noção de equivalência tautológica não é condição suficiente e só é condição necessária para equipolência nos casos de pensamentos compostos.

(iii) o critério de necessidade de consequência lógica torna válido todos os argumentos criados pelo critério lógico de equipolência, isto é, as equipolências entre pensamentos simples das linguagens naturais e todos os nove casos de pensamentos compostos.

Dado os três pontos acima, a conclusão mais plausível a respeito da aplicabilidade do critério lógico de equipolência parece ser a de que os nove casos de pensamentos compostos devem ser vistos como casos particulares de equipolência pela característica especial das fórmulas serem tautologicamente equivalentes. Esta característica particular permiti a aplicação do critério formal de consequência lógica no critério de equipolência lógico. Mas, como sabemos, não ocorre equipolência somente entre equivalências tautológicas.

Em contrapartida, o critério lógico de equipolência demonstrou ter aplicabilidade objetiva quando entra em questão o critério de necessidade de consequência lógica. Com esta ressalva foi possível compatibilizar exemplos de identidade de pensamentos, afirmados por Frege em diversos textos, com as exigências do critério lógico de equipolência. Devido aos fatos constatados, concluímos que o critério lógico de equipolência só é aplicável objetivamente com a noção intuitiva de consequência lógica, isto é, com o critério de necessidade da preservação da verdade e, como Frege buscava um critério lógico objetivo para reconhecer o mesmo pensamento dentre as várias formas linguísticas, parece que a nossa conclusão é a mais plausível possível.

\section{Referências bibliográficas}

BERMÚDEZ, José Luis. Frege on Thoughts and Their Structure. In: Williamson, Jon; Russo, Federica (Edits.). Logical Analysis and the History of Phylosophy. Vol. 4, 2003, pp. 1-23.

FREGE, Gottlob. Begriffsschrift, a formula language, modeled upon that of arithmetic, for pure thought (1879). In: Heijenoort, Jean van. From Frege to Gödel. A source book in Mathematical Logic. Cambridge: Harvard University Press. 1967, pp. 1-82.

Function and Concept (1891). In: Beaney, Michael. The Frege

Reader. $1^{a}$ ed., USA: Blachwell Publishing, 1997, pp. 130-148.

Review of E. G. Husserl, Philosophy of Arithmetic I (1894). In: Beaney, Michael. The Frege Reader. $1^{a}$ ed., USA: Blackwell Publishing, 1997, pp. 224-226.

Comments on Sense and Meaning (1892-1895). In: Beaney, Michael. The Frege Reader. $1^{a}$ ed., USA: Blackwell Publishing, 1997, pp. 
172-180.

A brief survey of my logical doctrines (1906). In Beaney, Michael. The Frege Reader. $1^{a}$ ed., USA: Blackwell Publishing, 1997, pp. 299-300.

Letter to Husserl (1906). In Beaney, Michael. The Frege Reader. $1^{a}$ ed., USA: Blackwell Publishing, 1997, pp. 305-307. On Sinn and Bedeutung (1892). In Beaney, Michael. The Frege Reader. $1^{a}$ ed., USA: Blackwell Publishing, 1997, pp. 151-171.

O Pensamento (1918). In Alcoforado, Paulo. Investigações

Lógicas. $1^{\mathrm{a}}$ ed., Porto Alegre: EDIPUCRS, 2002, pp. 14-37. A Generalidade Lógica (1923). In Alcoforado, Paulo. Investigações Lógicas. $1^{\text {a }}$ ed., Porto Alegre: EDIPUCRS, 2002, pp. 93-99. Pensamentos Compostos (1923). In Alcoforado, Paulo. Investigações Lógicas. $1^{\mathrm{a}}$ ed., Porto Alegre: EDIPUCRS, 2002, pp. 67-90. . Logic (1879-1891). In Long and White. Posthumous Writings. $1^{a}$ ed., England: Basil Blackwell, 1979, pp. 140-141.

THIEL, Christian. Sentido y Referência em la Lógica de Gottlob Frege. Espanha: Editor Madri Tecnos, 1972.

WEINER, Joan. Frege in Perspective. EUA: Editor Cornell University Press, 2008.

Frege Explained. From Arithmetic to Analytic Philosophy. EUA: Editor Open Court Publishing, 2005. 